\section{O TRAUMA DE TORTURA SOB A ÓTICA DA TEORIA DA SEDUÇÃO GENERALIZADA: VIVÊNCIAS DO PERÍODO CIVIL-MILITAR BRASILEIRO (1964-1985)}

Trauma of Torture under the Perspective of the Widespread Seduction Theory: Experiences from the Brazilian Civilmilitary Period (1964-1985)

\section{El Trauma de la Tortura bajo la Optica de la Teoria de la Sedución Generalizada: Vivencias del Periodo Civil-militar Brasileño (1964-1985)}

\section{Le Traumatisme de Torture sous L'optique de la Théorie de la Séduction Généralisée: Expériences de la Période Civile- Militaire Brésilienne (1964 - 1985)}

\section{Resumo}

O presente artigo investiga o trauma sofrido por sujeitos que foram submetidos à tortura na ditadura civil-militar brasileira compõem nosso material de análise: Retrato Calado, de Luiz Roberto Salinas Fortes, e Memórias do Esquecimento, de Flávio Tavares, que são analisados a partir da psicanálise, mais especificamente, da Teoria da Sedução Generalizada (TSG), de Laplanche. A TSG tem como premissa básica o trauma psíquico como constituinte do psiquismo humano; propõe a noção de mensagem enigmática enquanto impulsionadora de traduções; assinala o conceito de inconsciente estritamente sexual; e descreve a situação antropológica fundamental. A partir desses conceitos, tecemos algumas considerações acerca do trauma de tortura no que tange ao seu caráter sexual e disruptivo e propomos que a autointerrogação pode auxiliar no processo de tradução/elaboração do trauma.

Palavras-chave: trauma; tortura; ditadura civil-militar brasileira; narrativas testemunhais; teoria da sedução generalizada.

\section{Abstract}

This article investigates the trauma suffered by subjects who were submitted to torture in Brazilian civil-military dictatorship, through autobiographical narratives. Two books made up our analysis material: Retrato Calado, by Luiz Roberto Salinas Fortes, and Memórias do Esquecimento, by Flávio Tavares, which are analyzed from the psychoanalysis, specifically Laplanche's Theory of Generalized Seduction (Teoria da Sedução Generalizada - TGS). The $T G S$ has as basic premise the psychic trauma as a constituent of the human psyche; proposes the notion of cryptic message while conductor of translations; points out the concept of strictly sexual unconscious; and describes the fundamental anthropological situation. From these concepts, we weave some considerations about the torture of trauma in terms of their sexual and disruptive character and we propose that self questioning can assist in the process of translation / preparation trauma.

Keywords: trauma; torture; Brazilian civil-military dictatorship; witness accounts; general theory of seduction.

\section{Artigo Original}

1) Psicólogo, discente do Programa de Pós-graduação em Psicologia - PPI (UEM)

2) Psicólogo, Doutor em Psicologia do Desenvolvimento pela Universidade de São Paulo; Pós-doutorado em Psicanálise e Psicopatologia Fundamental pela Universidade de Paris VII; Professor dco Departamento de Psicologia da Universidade Estadual de Maringá.. 


\section{Resumen}

El presente artículo investiga el trauma sufrido por sujetos que fueron torturados en la dictadura civil-militar brasileña, por medio de narrativas autobiográficas. Dos libros componen nuestro material de investigación: Retrato Calado, de Luiz Roberto Salinas Fortes, y Memórias do Esquecimento, de Flávio Tavares, que son evaluados a partir de la psicoanálisis, más especificamente, de la Teoría de la Seducción Generalizada (TSG), de Laplanche. La TSG tiene como premisa básica el trauma psíquico como el constituyente del psiquismo humano; propone la noción de mensaje enigmático mientras impulsora de traducciones; marca el concepto de inconsciente estrictamente sexual; y describe la situación antropológica fundamental. Mediante estos conceptos, tejimos algunas consideraciones acerca del trauma de tortura en relación a su carácter sexual y disruptivo y propusimos que la auto interrogación puede ayudar en el proceso de traducción/ elaboración del trauma.

Palavras chave: trauma; tortura; dictadura civil-militar brasileña; narrativas de testigos; teoría de la seducción generalizada.

\section{Résumé}

Cet article analyse le traumatisme soufert par des sujets qui ont été sousmis à la torture dans la dictature civile-militaire bésilienne au moyen des récits autobiographiques. Deux livres composent notre matériel d'analyse: Retrato Calado, de Luiz Roberto Salinas Fortes et Memórias do Esquecimento, de Flávio Tavares. Ces livres-là sont analysés à partir de la psychanalyse, plus spécifiquement, à partir de la Théorie de la Seduction Généralisée (TSG) de Laplanche. La TSG a comme prémisse fondamentale le traumatisme psychique comme partie qui constitue le psychisme humain. Elle propose la notion de message énigmatique tandis que stimulatrice de traductions; marque le concept de l'inconscient strictement sexuel ; et décrit la situation antropophagique fondamentale. À partir de ces concepts on construit quelques considérations autour $d u$ traumatisme de torture en ce qui concerne son caractère sexuel troublant. On propose que l'auto-questionnement peut aider dans le processus de traducion lélaboration du traumatisme.

Mots-clés: traumatisme; torture; dictadure civile-militaire brésilienne; récit de témoignage; théorie de la séduction généralisée.

O presente artigo tem por objetivo investigar o trauma sofrido por sujeitos que foram torturados - no contexto da ditadura civil-militar brasileira (1964-1985) - a partir de narrativas autobiográficas publicadas anos após a vivência traumática. Utilizamos, como enfoque teórico, a psicanálise, mais especificamente, a Teoria da Sedução Generalizada
(TSG), de Laplanche (1992a), que tem como premissa a teoria do trauma como constituinte do psiquismo humano. Laplanche (1992a) desenvolve os conceitos de mensagens enigmáticas, situação antropológica fundamental (SAF), o inconsciente estritamente sexual e retoma e desenvolve a ideia de tradução de Freud (1896/1996a). Estes conceitos nos fornecem elementos importantes para a discussão do trauma decorrente da tortura, que trabalhamos neste artigo.

Nosso material de análise compõe-se de livros de cunho narrativo-testemunhais, escritos por ex-militantes políticos que foram presos e torturados. A princípio, foram lidos seis livros: Memórias Torturadas (e Alegres) de um Preso Político (1998), de Ildeu Manso Vieira; Ousar Lutar - Memórias da Guerrilha que Vivi (2007), de José Roberto Rezende; Em Câmara Lenta (1977), de Renato Tapajós; Tempo de Ameaça (1978), de Rodolfo Konder; Retrato Calado (1988), de Luiz Roberto Salinas Fortes; e Memórias do Esquecimento (2005), de Flávio Tavares. Os dois últimos foram escolhidos como material de análise, pois, devido à quantidade e qualidade de conteúdos subjetivos, suscitaram uma maior quantidade de associações livres e interpretações. Trabalhamos com essas narrativas no plano do singular, realizando uma "leitura flutuante" (Green, 1994, p. 16) de seus conteúdos, mas, também, buscamos algumas relações entre elas.

O tema da tortura no período da ditadura civil-militar brasileira é importante, pois, especificamente no Brasil, a ditadura durou 21 anos e foi um período que podemos considerar traumático, marcado por forte censura em todos os âmbitos da vida em sociedade. Mais que isso, trata-se de um período em que o uso da força e da violência de Estado foi notável. Aqueles contrários ao regime militar eram perseguidos, tendo que viver em clandestinidade, pois, se fossem encontrados, eram presos e torturados e, muitas vezes, assassinados. Sabemos, ainda, que esses regimes ditatoriais não se estabeleceram somente no Brasil, mas em vários países do mundo e principalmente na América Latina, nos chamados países do Cone Sul. Dentre estes países, encontram-se a Argentina, o Brasil, a Bolívia, o Chile, o Paraguai e o Uruguai. Apesar das peculiaridades de cada regime, todos seguiam os mesmos princípios ditos de segurança nacional que, segundo Coimbra (2000), tinham como premissa garantir a segurança nacional, mesmo que para isso fosse necessário o cerceamento da liberdade, a limitação das garantias constitucionais e dos direitos humanos, promulgados pela Organização das Nações Unidas (ONU), em 1948. De acordo com Viñar, Viñar e Bleger (1992, p. 134), “a tortura representou o papel da peça mestra no sistema de governo das ditaduras. Ela foi um meio privilegiado de manutenção do poder".

Nossa ideia de estudar a ditadura civil-militar brasileira partiu das discussões em torno da Comissão Nacional da Verdade, instaurada em 16 de maio de 2012 com o objetivo de apurar as violações dos direitos humanos, ocorridas 
no Brasil no período de 18 de setembro de 1946 até 5 de outubro de 1988 (Lei n. 12.528, 2011). Esta comissão percorreu o país na busca da restituição da verdade e do passado histórico. Passado este que não cessa de se fazer presente devido à ausência de muitas pessoas no seio de suas famílias e às marcas dos traumas da tortura, mas que por muito tempo foi silenciado pelo restante da sociedade brasileira.

Kehl (2010) considera que o esquecimento dos crimes de tortura ocasiona histórias inacabadas, com graves consequências para a sociedade. Trata-se, então, da naturalização da violência como um sintoma social. Sabemos que a tortura ainda é empregada em nosso país, o que mostra que este "sintoma" está longe de ser elaborado. Segundo Kehl (2010, p.124), "para a psicanálise, o esquecimento que produz sintoma não é da mesma ordem de uma perda circunstancial da memória pré-consciente: é da ordem do recalque". Acrescenta ainda que

(...) é possível afirmar que todo agrupamento social padece, de alguma forma, dos efeitos de sua própria inconsciência. São "inconscientes", em uma sociedade, tanto as passagens de sua história relegadas ao esquecimento - por efeito de proibições explícitas ou de jogos de conveniência não declarados - quanto as demandas silenciadas de minorias cujos anseios não encontram meios de se expressar. (Kehl, 2010, p. 124)

Ao contrário do que propõe Kehl (2010), acreditamos que essas histórias de violência e de violações ainda não foram recalcadas, pois não passaram pelo crivo da tradução e de sua consequente temporalização. O recalque, segundo Laplanche (1992a), pressupõe uma primeira tradução, que deixa restos não traduzidos e estes últimos dão origem ao recalcado (objetos-fonte). De acordo com Conte (2002), a violência da tortura evidencia a falha do recalque, aquilo que não foi traduzido, o cindido. $\mathrm{O}$ esquecimento é impossibilitado, pois o que atua é a compulsão, a repetição. Para ela, "a sociedade não esqueceu, pois não foi retraduzido. Há um silenciamento que não é esquecimento, mas sim uma cisão/ocultação (ao modelo de um fetiche) que tapa e obtura o que ocorreu" (Conte, 2014 ${ }^{1}$ ). Parece, pois, que a sociedade, as famílias das vítimas e os próprios vitimados têm ainda algo a traduzir, a decifrar, em relação à história recente do Brasil.

Aqui, a TSG é de grande valia, pois é uma teoria baseada na noção de trauma como constituinte do psiquismo e tem, como um de seus principais conceitos, a ideia de tradução. Segundo Laplanche (1993), a tradução pode ser compreendida no contexto clínico, que, de modo simplificado, é um processo a partir do qual algumas traduções realizadas pelo paciente são desfeitas

$\overline{1}$ Comunicação pessoal (destradução), para que, em um segundo momento, ocorram novas traduções (retradução) mais bem integradas ao psiquismo. Da mesma forma, acreditamos que a divulgação das vivências traumáticas, seja a partir de livros, relatos, artes, músicas, entre outros, pode proporcionar uma reordenação da história de muitas famílias brasileiras, a partir da "destradução" da história oficial proposta pelos militares e da construção de novas traduções acerca de suas experiências, possibilitando a elaboração destes traumas.

A noção de trauma é considerada muito importante para o desenvolvimento teórico da psicanálise, pois ela surge desde as primeiras explicações de Freud (1896/1996b) sobre a etiologia da histeria e permanece ao longo de sua obra. Podemos distinguir dois momentos na obra freudiana acerca do trauma. Embora consideremos que a noção de trauma foi sempre a mesma desde os anos de 1890, o que se modificou foi o contexto no qual ela foi utilizada. De acordo com Melo e Ribeiro (2006), se compararmos a primeira noção do trauma em Freud (1896/1996b), aquela da teoria da sedução, ao modelo apresentado em 1920, podemos conceber que o trauma sexual seria substituído pela pulsão de morte. Desta maneira, enquanto o primeiro modelo compreende um despreparo do organismo ante o ataque sexual por parte do outro, o segundo compreende um despreparo psíquico frente ao ataque da pulsão. No trauma de sedução, é a lembrança da vivência que, quando significada em um segundo momento, torna-se sexual, ocasionando o evento traumático. No segundo modelo, o evento traumático é a própria pulsão.

Ferenczi (1992) retoma a discussão do trauma sexual em psicanálise e propõe, em seu artigo "Confusão de Língua entre os Adultos e as Crianças", que há uma diferença entre a linguagem amorosa da criança, atravessada pela ternura, e a linguagem do adulto, atravessada pela paixão. Ferenczi (1992) afirma que adultos com algum perfil psicopatológico podem confundir as fantasias lúdicas da criança e interpretálas como um desejo sexual adulto (genital), respondendo com o abuso sexual. De acordo com Laplanche (1992a, p. 127), este artigo de Ferenczi (1992) pode ser considerado "uma espécie de prefácio à teoria da sedução generalizada", pois neste texto o autor discute a noção de trauma advindo da confusão de línguas, assinalando a assimetria entre adulto e criança. Assimetria esta que, para Laplanche (1992a), decorre da presença do inconsciente no adulto e da ausência deste na criança.

Laplanche (1985) também retoma a noção de apoio, apresentada por Freud (1915/1996c), que propôs que o desenvolvimento psicossexual se apoia em um mecanismo de conservação da vida, ou seja, a criança, ao entrar em contato com o seio materno, primeiramente, busca saciar a necessidade de alimento, mas, em um segundo momento, é iniciado o desenvolvimento da sexualidade. A teoria do apoio fundamenta a noção de "sedução originária" proposta por Laplanche (1985). O autor compreende o seio enquanto 
um significante enigmático, pois a mãe quando amamenta o filho também tem a sua sexualidade despertada, causando interferências na relação com a criança no sentido da transmissão de mensagens.

Assim, para Laplanche (1992a), a "sedução originária" compreende o (des)encontro entre a criança e o mundo adulto. O termo sedução originária comporta esta "situação fundamental em que o adulto propõe à criança significantes não verbais assim como verbais, inclusive comportamentais, impregnados de significações sexuais inconscientes" (Laplanche, 1992a, p.134). Essas mensagens atuam na criança enquanto enigmas que a interrogam e, ao mesmo tempo, demandam dela uma interpretação para a qual ela ainda não tem os recursos necessários (Laplanche, 1992a).

O primordial, para Laplanche (1992a), não é a sedução focal, mas a sedução originária, constituinte do ser humano, portanto generalizada. Nesse sentido, o autor adverte que o que Ferenczi (1992) denomina linguagem da paixão (linguagem do adulto) só é traumática porque transmite um sentido ignorado pelo próprio adulto. Mais do que isso, o que ocorre não é simplesmente uma confusão de línguas, como propõe Ferenczi (1992), mas sim "uma inadequação das linguagens, inadequação da criança ao adulto, mas também e primordialmente, inadequação do adulto em relação ao objeto-fonte que age nele mesmo" (Ferenczi, 1992, pp.138-139).

Essa situação originária entre criança e adulto, Laplanche (1992a) denomina de Situação Antropológica Fundamental (SAF), pois é ela que nos constitui enquanto seres humanos, ou seja, faz parte do nosso vir a ser no mundo. É algo que nos é intrínseco, tornamo-nos humanos por e a partir do outro que nos funda. Porém, a SAF é, também, essencialmente traumática devido à assimetria e ao excesso de energia advindo das mensagens enigmáticas com que a criança tem que lidar. A assimetria advém, sobretudo, das diferenças no desenvolvimento psíquico da criança, ainda sem inconsciente, e do adulto com o inconsciente já constituído.

A SAF pressupõe, ainda, uma relação de atividadepassividade, a posição ativa compreende a situação do adulto que envia mensagens enigmáticas à criança, que, por sua vez, encontra-se em uma situação de passividade, enquanto receptora dessas mensagens excessivas. Neste momento, a criança, segundo Laplanche (1992b), vivencia apenas certa presença no mundo, possibilitada, sobretudo, pelos órgãos do sentido. É somente em um segundo momento, aprèscoup, que o infante busca lidar com este excesso com as ferramentas que possui e com aquilo que lhe é fornecido pelo meio cultural e familiar, que Martens (2007) denomina de "ajudantes de tradução". As mensagens enquanto enigmas iniciam o infans no processo de temporalização, exigindo da criança um movimento autoteorizante para iniciar suas primeiras traduções, a partir das quais se dá o início do recalcamento originário.
Assim, as mensagens enigmáticas, por serem excessivas para a criança, são traumáticas, veiculando um excesso que pode ser excesso da falta e não somente da presença. Porém, são essas mesmas mensagens, enquanto enigmas, que fazem com que sejamos, segundo Laplanche (1992a), hermeneutas natos. De acordo com o autor, somos invadidos pela necessidade de traduzir tais enigmas, de dominá-los, iniciando assim o desenvolvimento de uma "pulsão interpretativa" que nos acompanhará pelo resto de nossas vidas. Mas, o autor pondera que as crianças, em suas primeiras tentativas de tradução destas mensagens, não conseguem traduzi-las e elaborá-las em sua totalidade, ficando restos não traduzidos que darão origem ao recalcado, isto é, à tópica freudiana, e tais restos são denominados por Laplanche (1992a) de "objetos-fonte" da pulsão.

Para Laplanche (1996), ainda cabe diferenciar duas categorias ou classes de mensagens: as mensagens implantadas e as mensagens intrometidas (variação violenta).

A implantação é um processo comum, cotidiano, normal ou neurótico. Ao lado deste, como sua variação violenta, é preciso dar lugar a intromissão. Enquanto que a implantação permite ao indivíduo uma resposta ativa, com seu duplo processo de tradução-recalque, é preciso conceber um processo que dificulte esta resposta, curto-circuita as diferenciações das instâncias em via de formação, e coloca no interior um elemento rebelde a toda metabolização. (Laplanche, 1996, p.106)

Para Laplanche (2003), a mensagem na SAF é sempre enigmática, em um primeiro momento, e somente no après-coup é reativada enquanto mensagem implantada ou intrometida, ou seja, somente após as primeiras traduções se revela como metabolizável ou não. Este esquema de tradução em dois tempos é o mesmo apresentado no modelo freudiano do trauma. A mensagem em um primeiro momento é simplesmente inscrita ou implantada, sem nenhuma compreensão. Ela se deposita em uma fina camada da consciência ou sob a pele (derme psicofisiológica). Em seguida, a mensagem passa a ser revivificada a partir do interior, agindo enquanto um corpo estranho, impondo ao sujeito uma necessidade de integrá-lo e controlá-lo.

A partir destas considerações, propomos algumas questões que nos ajudam a pensar o tema de nosso estudo: quais elementos presentes na SAF poderiam nos ajudar a compreender melhor o trauma de tortura? Quais seriam as características da mensagem presentes na situação de tortura e quais consequências elas podem gerar? De que forma a escrita das narrativas de testemunho poderia contribuir na elaboração do trauma?

Supomos, pois, que a situação de tortura reatualiza elementos semelhantes à vivência da SAF. Porém, nos casos de tortura, as mensagens emitidas seriam, em sua maioria, 
vivenciadas enquanto intromissão por parte de seu receptor, devido à característica violenta da situação. Estas mensagens se relacionam com a noção de inconsciente encravado, que corresponde à instância psíquica depositária das mensagens que não passaram pelo crivo da tradução justamente pelo fato de terem sido intrometidas com violência.

Outra hipótese que expomos aqui é a de que as narrativas de testemunho, escritas ou contadas por sobreviventes de tortura, podem dar início às primeiras traduções destas mensagens intrometidas. O escrever ou falar envolveria, então, o processo de temporalização ou elaboração das vivências traumáticas.

Pois bem, apresentamos agora a análise das narrativas autobiográficas: Retrato Calado (Fortes, 1988) e Memórias do Esquecimento (Tavares, 2005). A partir de nossas análises gerais, que tiveram como inspiração o estudo já empreendido por Fernandes (2008), levantamos alguns pontos específicos comuns a ambas as narrativas. Esses pontos, organizados em forma de categorias, são: o sexual da tortura e seu aspecto disruptivo; e o processo de autointerrogação enquanto auxiliar para novas traduções, discutidos a seguir.

\section{O Sexual da Tortura e seu Aspecto Disruptivo}

No período da ditadura civil-militar brasileira, foi declarada "guerra" contra o comunismo, uma guerra dita "interna", dentro das fronteiras do país, de forma que o indivíduo que era contra ou que era visto como contra o regime político vigente era considerado inimigo da pátria, e sabemos que a ideologia da guerra "facilita", dá pretexto para que nosso pulsional desligado, o polimórfico perverso, possa atuar contra o outro, que já não é mais um semelhante e sim um inimigo. É este pulsional desligado que deixa Fortes (1988) perplexo ao perceber a ironia que antecede o prazer sádico do torturador, conforme aponta Fernandes (2008). Ao relatar a rotina da vida na prisão, Fortes (1988) traz situações permeadas pelo sexual perverso polimórfico:

E lá vem o PM de plantão, que aciona a descarga instalada no muro do corredor ao lado de fora da cela. Perder a liberdade é também ser privado de qualquer controle sobre os odores próprios e alheios, dos companheiros amontoados nos aromáticos aposentos. (...) Infantilização impiedosa e indesejável intimidade, quase cumplicidade entre vítima e algoz, empenhados na mesma tarefa de reprodução quotidiana da celestial mecânica. Promiscuidade infamante, elemento a mais no processo de trituração: como resistir? (Fortes, 1988, p.23)

Pode-se ver aí o quanto a vivência na prisão se baseia na dependência. $\mathrm{O}$ prisioneiro fica à mercê das vontades de quem o vigia. Há aí uma relação estabelecida, mas o diálogo é desigual. Relação de extrema dependência e assimetria, que faz com que o sujeito se sinta infantilizado. Sabemos que, nas origens, há uma situação desigual entre adulto e criança, na qual o que está em jogo é a sexualidade transbordante do adulto frente à passividade e à impossibilidade da criança em conter o excesso sexual. No excerto acima, claramente, a situação é vivenciada como algo excessivo por parte de Fortes: "infantilização impiedosa e indesejável". Há, ainda, a presença do sexual que se entremostra a partir das fezes. Não é preciso argumentar muito para supor que esta posição infantil desencadeia uma regressão, já que, de forma inconsciente, algumas vivências infantis podem ser rememoradas.

Outro exemplo da sexualidade que é veiculada no ambiente de prisão e tortura, apresentado por Fortes (1988), diz respeito a um investigador que gostava de se exibir:

Há um investigador, corpulento e careca, sempre com um terno azul-marinho, gravata e tudo, que gosta, quase todas as noites, de se exibir gratuitamente para os presos políticos, embora disfarçado e parecendo entretido exclusivamente com suas vítimas. (...) Depois, o careca divertia-se, junto com os colegas, enquanto mandava a prisioneira varrer o pátio interno do pavilhão, dizendo que mais tarde ia comer a negra e já ficando de cuecas em meio à algazarra geral. (Fortes, 1988, p.24)

Novamente a sexualidade aparece e o que nos é interessante aqui é a ordenação do relato do autor, que primeiramente fala sobre a infantilização e a dependência vividas enquanto prisioneiro e, em seguida, aborda o exibicionismo do investigador ao maltratar suas vítimas. Sabemos que se há um exibicionista, existe também um voyeur. Neste caso, os prisioneiros, inclusive Fortes, estão submetidos ao exibicionismo do investigador, mas, ao mesmo tempo, também participam da cena ao observá-lo. Os elementos da sexualidade infantil aí parecem indicar que o que está em jogo na situação de prisão-tortura é o sexual em sua forma mais perverso-polimórfica e, portanto, infantil.

A vítima é sujeitada a uma passividade extrema em que não possui controle do seu corpo e dos seus sentidos, e pode se questionar "o que ele quer de mim, além de me torturar?" No decorrer do livro de Tavares (2005), percebemos que ele busca traduções ou novas formas de compreensão da tortura, talvez buscando respostas para esta pergunta, como podemos perceber quando o autor afirma que: "Eles não são assassinos, apenas torturadores, o estágio mais alto do sadismo" (Tavares, 2005, p.35). Mais adiante, ao descrever uma cena de tortura, o sexual está presente na forma de sadismo, que pressupõe que o algoz procura o prazer:

Os tapas continuaram, o torturador cada vez mais perto, mais perto, até encostar a cara na cara de Ivan, o corpo 
no corpo de Ivan, sempre lhe dando mais golpes, cada vez unindo mais rosto com rosto, quase beijando a vítima, cheirando-lhe o pescoço, como se aquilo não fosse tortura, mas o êxtase do torturador estuprando o prisioneiro pelos ouvidos. (...) De pronto, estremeceu como se chegasse à ejaculação (...). (Tavares, 2005, p.94)

Nesta cena, o caráter sexual que permeia a experiência de tortura fica evidente. O torturador aqui está gozando de forma sádica, como aponta Fernandes (2008). Qual seria a mensagem enigmática transmitida para a vítima nessa cena tão abertamente sexual? Supomos que o perverso polimórfico do torturador é reatualizado na situação de tortura e as mensagens que ele envia são sobretudo intrometidas. É evidente que a intromissão aqui se dá a partir do pulsional desligado, que subjuga o corpo da vítima de forma parcial. O sexual da tortura é excessivo e, embora o adulto já seja dotado de defesas egoicas, supomos que de início nada é traduzido, embora après-coup haja alguma interpretação/simbolização do desejo do torturador.

$\mathrm{O}$ excesso que advém das práticas de tortura se deve à forma parcial como a sexualidade é intrometida no corpo e no psiquismo da vítima. Esta intromissão se dá de forma anal e oral, literalmente, conforme descreve Tavares (2005) acerca dos choques elétricos:

$\mathrm{Na}$ sala de torturas, o prisioneiro está sempre nu ou seminu (só de cuecas ou calcinhas) e isto, que em si mesmo já é uma humilhação, facilita o requinte maior do choque elétrico: nos homens, amarrar os fios no pênis, e nas mulheres, introduzir o cabo metálico na vagina. E em ambos, como alternativa final, o choque elétrico no ânus. (Tavares, 2005, p.39)

O psiquismo do torturado é invadido por um excesso de alteridade, de forma que os elementos do sexual desligado do torturador permanecem impregnados na psique da vítima, encravados, não traduzidos, à espera de tradução. Esta necessidade de traduzir o excessivo da experiência de tortura é tanta que Fortes (1988) a compara a um exorcismo, que ilustra a profanação da alma do sujeito e faz pensar em algo como outra entidade atuando no interior do indivíduo:

E hoje o exorcismo que se renova a cada instante, a cada hora, a cada dia, a cada semana, a cada mês, a cada ano, a esperança que rejuvenesce de quebrar as grades, voar, essas grades que continuam, imaginárias, a me comprimir o cérebro. Sonho em reconquistar a integridade e a liberdade, será possível? Como contornar a lógica da tendência se o sabotador, com toda sua malícia, instalouse dentro da cabeça, enfiou-se no interior do interior, sugando os esforços e comprometendo a objetividade do pensamento? (Fortes, 1988, p.100)
Fernandes (2008), ao apresentar este excerto, discorre sobre a ambiguidade presente no processo da escrita, ou seja, a necessidade de relembrar para esquecer, e associa a noção de exorcismo ao desejo de Fortes de livrar-se de um fardo que carrega. Para nós, se pensarmos na lógica do aprés-coup, é de se supor que a mensagem é revivificada como intrometida, porém há a tentativa de elaboração/ tradução a partir da escrita, bem como um movimento de interrogar-se que abordaremos mais adiante.

Esta noção de uma entidade que age no interior do indivíduo enquanto corpo estranho nos aproxima da proposta de Cardoso (2000) a respeito do superego. Para a autora o superego estaria do lado do fracasso radical de tradução, nada seria traduzido e permaneceria no inconsciente encravado. Os estados traumáticos produzemse de um fracasso em traduzir e os enclaves, por sua vez, se formariam a partir de um fracasso de tradução.

Diante da impossibilidade de traduzir e de des-traduzir, o sistema do ego transborda. Esse transbordamento corresponde, de fato, à ação da des-ligação, esta última implicando não apenas que o sistema egoico seja transtornado, mas também que o ego volte contra si mesmo os aspectos que o atacam. O ego aqui é passivo em relação ao superego, em relação a esse representante da "realidade da mensagem". (Cardoso, 2000, p.34)

É bastante aceitável que o sujeito frente ao trauma também se encontre em um estado que o impossibilite de traduzir e destraduzir, isto se deve ao excesso traumático que invade o psiquismo e ocasiona o transbordamento do ego. Desta forma, o ego se encontra desprovido de defesas frente ao desligamento pulsional ocasionado pelo trauma, este último agora vivido do interior (autotrauma). Podemos pensar que no instante traumático, o psiquismo é inundado pelo pulsional desligado, que compromete a integridade do ego, que, sem recursos para lidar com ele, precisa recorrer a mecanismos de defesa mais arcaicos relacionados à estruturação egoica. De acordo com Carvalho (2012, p. 96), "face ao acontecimento traumático, o sujeito encontra-se completamente desamparado, o que reproduz necessariamente a situação de passividade originária". Assim, compreendemos que o que ocorre é uma regressão à fase de constituição psíquica, semelhante ao momento do trauma originário, na qual o ego lança mão de defesas narcísicas, tais como o masoquismo originário, a fim de estabelecer barreiras frente ao excesso.

Andrade (2011), a partir das ideias de Laplanche, propõe que: "o masoquismo (originário) consiste numa resposta (tradução) narcísica e defensiva, complementar e diametralmente oposta ao enigma lançado por um adulto cujas mensagens sexuais inconscientes revelaram traços predominantemente sádicos, no contexto da sedução inerente à relação criança-adulto" (Andrade, 2011, pp.56- 
57). Para Conte (2002, p. 90), a disposição masoquista é uma forma "de erotização deste primeiro momento traumático de intromissão de um 'outro sujeito' que engendra o excesso de excitação, correspondendo à pulsão de morte (...) [o masoquismo] constitui o tempo inicial da pulsão e a forma precoce de trabalhar com a fusão pulsional". Aqui a concepção de masoquismo originário também é entendida enquanto uma defesa arcaica.

Podemos supor que o que é reativado na vítima de acontecimentos traumáticos, em seu aspecto defensivo, seria justamente estas primeiras defesas que visam à reestruturação do ego. Em uma primeira análise, poderíamos pensar que em algumas vítimas de tortura o seu masoquismo erógeno poderia ser "despertado", mas acreditamos que, muito mais do que o masoquismo erógeno, o que seria ativado na vítima estaria mais relacionado ao masoquismo originário. Assim, compreendemos que o masoquismo seria a saída narcísica encontrada pelo ego para lidar com o excesso sádico. "O prazer reside não na dor, mas na capacidade de suportá-la, tanto para sobreviver psiquicamente a quadros de privação e maus-tratos quanto para negar a dependência em relação àquele que faz sofrer" (Andrade, 2012, pp.454-455).

\section{Interrogar-se para Traduzir: A Filosofia do Trauma}

Nas narrativas analisadas, percebemos a "necessidade" dos autores de recontar suas histórias a partir da escrita. Esta necessidade se dá por meio da pulsão que se impõe ao sujeito e o impulsiona a traduzir, mas estas características de imposição e de insistência deixam aparente o caráter intrometido da mensagem, que podemos comparar ao que emerge enquanto, como nos diz Laplanche (1992b), imperativo categórico vindo do superego, do tipo "deciframe ou te devoro". Porém, como vimos, mesmo as mensagens enigmáticas intrometidas são passíveis de tradução. E, de acordo com Cardoso (2011, p. 78), "aquilo que não pode ser traduzido tende a se repetir como um imperativo, o que em muito difere da condição propriamente neurótica".

Mas, como traduzir, se o imperativo não se transmuda em nada, senão nele mesmo? Como fugir do ciclo de repetição?

A escrita é um caminho na tentativa de elaboração do traumático, mas, para se chegar até ela, há que se abrir novas vias autoteorizantes. Em ambos os livros por nós analisados, percebemos de forma recorrente a presença de muitos pontos de interrogação e perguntas realizadas pelos autores durante a narrativa. Este fato nos chamou a atenção. Para que tantos questionamentos? Por que tantas perguntas (por vezes, sem respostas)?

$\mathrm{Na}$ introdução de seu livro, Tavares (2005) apresenta vários questionamentos acerca dos motivos que o levam a escrever:
Por que lembrar o major torturador, os interrogatórios dias e noites adentro? Por que trazer de volta aquele sabor metálico do choque elétrico na gengiva, que me ficou na boca meses a fio? Por que lembrar a prisão em Brasília ou no Rio de Janeiro ou nos quartéis de Juiz de Fora? (Tavares, 2005, pp. 13-14).

Fortes (1988) também se questiona sobre os motivos de sua escrita, e propõe algumas respostas:

A única coisa que sou capaz de dizer no momento é que se as escrevo - as memórias - é para dar a mim mesmo, conceder-me em benefício próprio, uma 'ANISTIA AMPLA GERAL E IRRESTRITA', já que ninguém me concede. Por que não? Quem impede? Uso deste espaço para não deixar que tudo se perca, se evapore. E continuo dizendo dessa forma canhestra e imprecisa, infiel e abstrata. $O$ fato é que tudo mudou, que era o mundo antes, o meu, bem diferente. E tudo vai ficar por isso mesmo? (Fortes, 1988, p. 80)

Fernandes (2008) afirma que os motivos da escrita de Fortes advêm da obrigação do registro histórico, de sua necessidade pessoal de elaboração e da vontade de esquecer estas experiências. Assim, percebemos que no processo de escrita, para que possa traduzir e elaborar, o sujeito precisa rememorar e narrar o trauma. É aí que se encontra o paradoxo do trauma: para esquecer é preciso, primeiro, rememorar. Embora o que o escritor busque seja esta anistia de que nos fala Fortes (1988), que permitirá o esquecimento da figura do torturador que invade o psiquismo do torturado, esta só é possível a partir da lembrança e da revivescência do trauma. Revivescência esta que não pode ser sua simples repetição, mas a repetição que abre caminho para o novo, para novas traduções possíveis, que dê novos sentidos ao que é da ordem do encravado.

Acreditamos que a abertura deste novo caminho se inicie a partir do processo de autointerrogação. Podemos comparar o interrogar-se com a curiosidade infantil, processo de autoteorização que corresponde às primeiras traduções por parte do infante. No adulto torturado, a dificuldade em iniciar o processo de tradução é maior, devido à intromissão da mensagem, que permanece em estado bruto no psiquismo, no "limbo" proposto por Laplanche (2003). A partir da autointerrogação, o sujeito é impulsionado a realizar traduções pré-conscientes, que confeririam novas significações para aquilo que até então era inominável. Assim, propomos que o interrogar-se é necessário para a tradução, ou seja, o processo de questionamento se relaciona com a capacidade do sujeito em iniciar o processo de tradução que permitirá a metabolização da mensagem intrometida. Desta forma, a escrita atua como uma ferramenta que contribui para a elaboração do trauma, pois 
envolve um processo mental que ajuda o sujeito a elaborar questões, fazer conexões e realizar ligações.

No decorrer de suas construções narrativas, os autores vão tecendo questionamentos e, ao mesmo tempo, formulando algumas respostas e elaborando traduções mais complexas. No entanto, pudemos também perceber que os autores deixam muitos de seus questionamentos em aberto, sem os concluir. É muito possível, pois, que, embora a escrita contribua com o processo de elaboração, algumas das interrogações permaneçam sem respostas, pois o que está sendo questionado é da ordem do inconsciente, do encravado. E também, como propõe Laplanche (1992a), a tradução é um processo que nos acompanha a vida toda, pois da tradução sempre sobram restos, que continuam a nos impulsionar para novas traduções.

Assim, percebemos que Tavares (2005), ao final de seu texto, embora já apresente um nível de elaboração estruturado, continua a interrogar-se:

De onde me vem esse ardor de perigo, essa paixão pela morte que não morri? Por ser um sobrevivente? (...) Terei namorado sempre a morte? Sem coragem para o suicídio - esta aflição dos adolescentes e jovens da minha geração no sul do Brasil -, terei optado por esse caminho da luta armada, mesmo quase sem armas, porque isso disfarçava tudo, principalmente a falta de coragem para me matar de forma mais direta, desiludido de uma sociedade falsa e injusta ou (mais fútil e mais simples) deprimido pela frustração amorosa de jovem? (Tavares, 2005, pp.292293)

Esses questionamentos abrem caminho para traduções outras, talvez mais complexas e profundas, que continuarão a impulsionar o autor no caminho da autoteorização.

Por fim, salientamos que o modo como este interrogarse vai ocorrer dependerá da forma como se deu a vivência traumática, dos recursos psíquicos do sujeito e dos ajudantes de tradução presentes em seu meio cultural, social e familiar. Neste sentido, consideramos as traduções construídas por Tavares (2005) mais elaboradas, em relação àquelas apresentadas por Fortes (1988), fato que pode estar associado ao tempo em que cada uma das narrativas foi escrita, evidenciando a ação do après-coup, já que Tavares iniciou seu processo de escrita com um distanciamento de quase 30 anos em relação à vivência traumática, enquanto presumimos que Fortes o tenha iniciado poucos anos após as experiências de tortura.

Acreditamos que nem todas as pessoas que passaram por situações traumáticas como a tortura irão realizar um processo de autointerrogação como o percorrido pelos autores das narrativas que analisamos. Muitas pessoas podem chegar a este processo a partir da ajuda encontrada em seu meio social, outras encontram uma saída a partir da análise, muitos buscam na escrita um amparo, outros continuam na militância, na política, e há aqueles que realmente sucumbem às mazelas do trauma de tortura $\mathrm{e}$ acabam enlouquecendo ou até mesmo cometendo suicídio, como no caso de Frei Tito de Alencar (Betto, 1983).

\section{Considerações Finais}

Diante do exposto, podemos considerar que, guardadas as devidas proporções, a vivência de tortura pode ser comparada com a SAF a partir de algumas de suas características, que são: uma relação assimétrica, de atividade-passividade, traumática por excelência.

Como vimos, a relação entre torturadores e torturados é estabelecida entre adultos, já "dotados" de inconsciente, mas marcada por uma forte assimetria. A assimetria decorre da impotência da vítima frente ao trauma, já que o estado de debilitação do corpo do sujeito torturado provoca, também, a debilidade de seu psiquismo, que se encontra sobrecarregado pelo excesso com o qual tem de lidar. As defesas do ego, devido a sua desestruturação, já não funcionam da mesma maneira que antes da tortura, de modo que o indivíduo responde ao trauma a partir de defesas psíquicas mais arcaicas, como o masoquismo originário, que visam à reestruturação egoica.

A relação originária (SAF) também é considerada uma situação traumática por excelência, haja vista as implicações das mensagens enigmáticas no psiquismo do infante. Nas práticas de tortura, podemos conceber que a relação também é, no mínimo, traumática, porém temos que considerar que as mensagens recebidas nesta situação são, em sua maioria, vivenciadas après-coup enquanto intromissão, devido à violência das práticas de tortura. Esta intromissão veicula principalmente o pulsional desligado do torturador, que é reativado pelo polimórfico-perverso contido na própria situação de tortura, talvez até na própria ideia de tortura. O psiquismo do torturado é invadido por um excesso de alteridade, experimentado pelo ego como algo excessivo. O trauma, dito atual, reatualiza lembranças de traumas anteriores e, devido à especificidade da tortura, esta reatualização pode remeter a tempos mais arcaicos, ao período da SAF.

Consideramos que a escrita auxilia no processo de elaboração do trauma e a partir das narrativas percebemos outro mecanismo que pode atuar neste mesmo sentido. Acreditamos que a autointerrogação seria este auxiliar que, por sua vez, iniciaria o processo tradutivo, possibilitando a abertura de novas vias autoteorizantes para lidar com o traumático. Propomos, então, que o interrogar-se seria uma pré-condição para traduzir e impulsionaria o sujeito a buscar respostas, rompendo com o "fetichismo narrativo" (Santner, 1992 citado por Fernandes, 2008), que caracterizamos pela recusa em traduzir. No entanto, acreditamos que nem todos que vivenciaram situações traumáticas possuem recursos 
para iniciar este processo autoteorizante, necessitando buscá-los por outras vias, que podem ser: a partir do meio social, da análise, da escrita, da militância, da política e, em última instância, do suicídio.

\section{Referências}

Andrade, F. C. B. (2011). A metapsicologia do masoquismo em Freud e Laplanche. Estudos de Psicanálise, (36), 55-68.

Andrade, F. C. B. de. (2012). Masoquismo e mensagem enigmática: Para que rimar amor e dor? Psicologia em Estudo, 17(30), 453-462.

Betto, F. (1983). Batismo de sangue: Os dominicanos e a morte de Carlos Marighella (6 ${ }^{\mathrm{a}}$ ed.). Rio de Janeiro: Civilização Brasileira.

Cardoso, M. R. (2000). O superego: Em busca de uma nova abordagem. Revista Latino-americana de Psicopatologia Fundamental, 3(2), 26-41.

Cardoso, M. R. (2011). Das neuroses atuais às neuroses traumáticas: Continuidade e ruptura. Revista Latinoamericana de Psicopatologia Fundamental, 1(14), 7082.

Carvalho, M. T. M. (2012). Sofrimento psíquico, acontecimento traumático e angústia pulsional. Psicologia em Estudo, 17(3), 487-497.

Coimbra, C. M. B. (2000). Doutrinas de segurança nacional: Banalizando a violência. Psicologia em Estudo, 5(2), $1-22$.

Conte, B. S. (2002). Prazer e dor: O masoquismo e a sexualidade. Porto Alegre: Criação Humana.

Ferenczi, S. (1992). Confusão de língua entre os adultos e as crianças. A linguagem da ternura e da paixão. In S. Ferenczi, Obras Completas de Sándor Ferenczi (Vol. 4). São Paulo: Martins Fontes.

Fernandes, F. F. (2008). A escritura da dor: Testemunhos da ditadura militar. Tese de Doutorado, Instituto de Estudos da Linguagem, Universidade Estadual de Campinas, Campinas-SP.

Fortes, L. R. S. (1988). Retrato calado. São Paulo: Marco Zero.

Freud, S. (1996a). Carta 52. In J. Strachey (Ed.), Edição

Standard Brasileira das Obras Psicológicas Completas de Sigmund Freud (Vol. 3). Rio de Janeiro: Imago. (Originalmente publicado em 1896)

Freud, S. (1996b).Aetiologia da histeria. In J. Strachey (Ed.), Edição Standard Brasileira das Obras Psicológicas Completas de Sigmund Freud (Vol. 3). Rio de Janeiro: Imago. (Originalmente publicado em 1896)

Freud, S. (1996c). Os instintos e suas vicissitudes. In J. Strachey (Ed.), Edição Standard Brasileira das Obras Psicológicas Completas de Sigmund Freud (Vol. 14). Rio de Janeiro: Imago. (Originalmente publicado em 1915)

Green, A. (1994). O desligamento: Psicanálise, antropologia e literatura. Rio de Janeiro: Imago.

Kehl, M. R. (2010). Tortura e sintoma social. In E. Teles, \& V. Safatle (Orgs.), O que resta da ditadura (pp. 123132). São Paulo: Boitempo.

Konder, R. (1978). Tempo de ameaça. São Paulo: AlfaÔmega.

Laplanche, J. (1985). Vida e morte em psicanálise. Porto Alegre: Artes Médicas.

Laplanche, J. (1992a). Novos fundamentos para a psicanálise. São Paulo: Martins Fontes.

Laplanche, J. (1992b). Problemáticas IV: O inconsciente e $o$ id. São Paulo: Martins Fontes.

Laplanche, J. (1993). A tina: A transcendência da transferência. São Paulo: Martins Fontes.

Laplanche, J. (1996). La prioridad del otro em psicoanálisis. Buenos Aires: Amorrortu.

Laplanche, J.(2003). Trêsacepções dapalavra "inconsciente" no quadro da teoria da sedução generalizada. Revista de Psicanálise, 10(3), 403-418.

Lei n. 12.528, de 18 de novembro de 2011. Cria a Comissão Nacional da Verdade no âmbito da Casa Civil da Presidência da República. Brasília, DF: Presidência da República. Recuperado de http://www.planalto.gov.br/ ccivil_03/_Ato20112014/2011/Lei/L12528.htm

Martens, F. (2007). Para una validación sócio-clínica de la teoria de la seducción generalizada. ¿Una contribución de los pedófilos belgas? Alter, 7, (s.p.). Recuperado de http://revistaalter.com/revista/para-una- 
validacion-socio-clinica-de-la-teoria-de-la-seducciongeneralizada/767/

Melo, M. T., \& Ribeiro, P. C. (2006). Modelos do trauma em Freud e suas repercussões na psicanálise pósfreudiana. Percurso, (37), (s.p.). Recuperado de http:// revistapercurso.uol.com.br/index.php?apg=artigo_ view\&ida $=249 \&$ ori $=$ edicao\&id_edicao $=37$

Rezende, J. R. (2007). Ousar lutar: Memórias da guerrilha que vivi [Depoimento a Mouzar Benedito]. São Paulo: Viramundo.

Tapajós, R. (1977). Em câmara lenta. São Paulo: AlfaÔmega.

Tavares, F. (2005). Memórias do esquecimento ( $5^{\mathrm{a}} \mathrm{ed}$.). Rio de Janeiro: Record.

Vieira, I. M. (1998). Memórias torturadas (e alegres) de um preso político. Maringá: EDUEM.

Viñar, M., Viñar, M., \& Blejer, L. (1992). Reflexões sobre uma clínica da tortura. In M. Viñar \& M. Viñar (Orgs.), Exílio e tortura (pp. 133-149). São Paulo: Escuta.

\section{Endereço para correspondência:}

Renan Martimiano Vieira

Endereço: Rua Mandaguari, nº 198, apto 503, Zona 7.

Maringá/PR, CEP: 87.020-230.

E-mail: martimiano86@gmail.com

\section{Endereço para correspondência:}

Gustavo Adolfo Ramos Mello Neto

Endereço: Rua Professor Ney Marques, n 21, Zona 7. Maringá/PR, CEP: 87.020-300.

E-mail: garmneto@gmail.com 